\title{
Variability of Vernier acuity measurements in untrained subjects of different ages
}

C.M.M. Abbud and A.A.V. Cruz

\author{
Departamento de O ftalmologia, Otorrinolaringologia e Cabeça e Pescoço, \\ Faculdade de Medicina de Ribeirão Preto, Universidade de São Paulo, \\ Ribeirão Preto, SP, Brasil
}

\section{Correspondence \\ A.A.V. Cruz \\ Departamento de Oftalmologia, \\ Otorrinolaringologia e \\ Cabeça e Pescoço \\ Hospital das Clínicas, FM RP \\ Av. Bandeirantes, 3900 \\ 14048-900 Ribeirão Preto, SP \\ Brasil \\ E-mail: aavecruz@ fmrp.usp.br \\ Publication supported by FAPESP.}

Received November 30, 2000

Accepted December 4, 2001

\section{Abstract}

The Vernier acuity of 50 normal untrained subjects (20 males and 30 females) was measured by the method of adjustment. Subjects were divided into five age ranges with 10 subjects in each age group: 5-10, 11-20, 21-30, 31-40, and 41-50 years. All subjects had normal visual acuity (20/20) and volunteered to participate in the experiment. Children were selected from a local school and adults recruited from the technical staff of the Department of Ophthalmology of the School of Medicine. Vernier acuity was higher in adults compared to children. Intraindividual variability was high and it was estimated that for most individuals of all age groups a range of 100 to 700 trials was necessary to obtain a mean with a precision of $10 \%$. These results suggest that Vernier acuity variability is an obstacle to its use in clinical settings.
Key words

- Vernier acuity

- Variability

- Age

\section{Introduction}

Vernier acuity is a peculiar type of visual task that involves the ability of the visual system to locate an object relative to another (1). This type of resolution, also called positional acuity, is usually measured in seconds of arc as the smallest detectable misalignment between two abutting stimuli such as bars, lines or dots (2).

Like any other visual threshold, Vernier acuity can be measured with a variety of psychophysical methods, e.g., staircase or limits, constant stimuli and adjustment methods (3). The method of adjustment has been successfully used for clinical testing of Vernier acuity, especially for untrained and older observers $(2,4)$. Furthermore, this method facilitates the rapid distinction between Vernier accuracy (mean offset error) and precision (standard deviation) (4).

Unlike Snellen acuity, which depends primarily on intercone spacing (sampling theorem) (5,6), Vernier acuity belongs to a class of localization tasks termed hyperacuities because, under optimal presentation conditions, the thresholds are extremely low (of the order of 3-5 arc s), which is smaller than the diameter of a single foveal cone ( 25 to 30 arc s) (7-9). Several psychophysical factors involved in the Vernier acuity response have been extensively studied. The effect of optical blur (10), stimulus configuration (11), luminance (12), motion (13), spatial frequency (14), line orientation $(15,16)$ and other parameters of the Vernier thresh- 
olds are well known.

The Vernier paradigm is not used frequently in ophthalmology. Few investigations have been performed using Vernier acuity to test patients with eye diseases (17). The lack of clinical studies on Vernier acuity is probably related to the strong effect that practice has on the magnitude of the Vernier threshold $(1,18,19)$. In clinical settings, time is a very important factor and extremely long psychophysical examinations are not feasible.

The objective of the present study was to investigate the number of Vernier trials necessary to obtain a mean value with a precision of $10 \%$ in untrained subjects.

\section{Material and Methods}

All tests were performed in a darkened room with subjects located $10.73 \mathrm{~m}$ from a flat 17" computer monitor. Two vertical white lines, each 0.5 arc min wide and 5 arc min high, were generated using a microcomputer and presented one above the other on the monitor with a 1-min gap between them. The upper line was stationary in the center of the screen while the position of the bottom line could be moved horizontally using a track ball (method of adjustment).

Before testing began, a series of 10 practice trials was run under binocular conditions. This short session, which typically lasted less than $5 \mathrm{~min}$, was performed just to

Figure 1. Effect of age on Vernier acuity. Age groups: $1=5-10$, $2=11-20,3=21-30,4=31-40$, and $5=41-50$ years. The symbols reported as arc $\mathrm{s}$ represent the mean offset. The bars indicate the $95 \%$ confidence interval of the mean for 10 subjects in each group and 10 measurements for each subject.

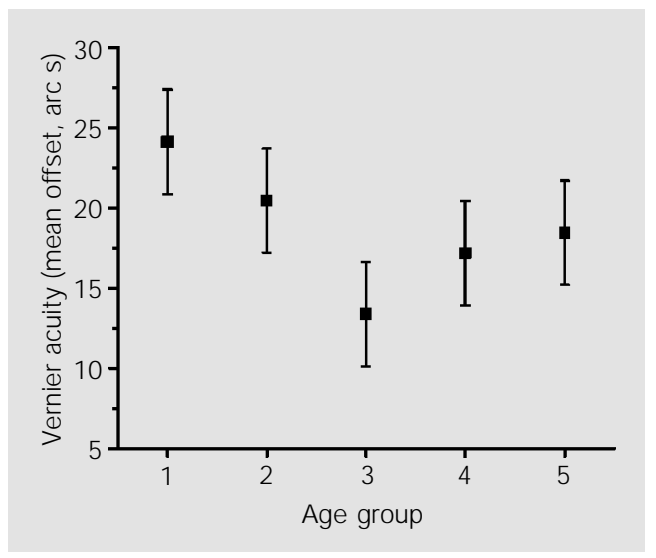

familiarize the subject with the testing conditions and the nature of the measurement. All subjects understood the procedure after just one session. According to the literature, this short number of trials does not induce any training effect on the threshold magnitude.

Data were collected under monocular viewing conditions (right eye). During monocular testing, the subjects wore orthoptic eye patches (left eye). The test consisted of 10 trials for each subject which typically lasted about $5 \mathrm{~min}$. The distance of the variable line from the fixed line was varied at random across trials. Subjects were instructed to move the bottom line so that it was exactly below the upper one. Once they were satisfied that the lines were exactly aligned, the examiner pressed the enter key on the track ball and the computer measured the location of the bottom line in seconds of arc. The threshold was the arithmetic mean of the offset for the 10 trials. Due to limitations in room space and pixel size $(0.26 \mathrm{~mm})$, the smallest misalignment that could be measured was 5 arc s.

We tested the Vernier acuity of 50 subjects divided into five age ranges with 10 subjects in each age group: 5-10, 11-20, 21 $30,31-40$, and $41-50$ years. The mean age of each group was 6.9, 14.9, 26.3, 35.7, and 44.8 years. All subjects had 20/20 visual acuity in each eye optically corrected when necessary with spectacles. All 500 measurements were performed using the right eye.

\section{Results}

The mean Vernier acuity in each age group for 10 trials is presented in Figure 1. One-way analysis of variance (ANOVA) indicated that there were significant differences between mean thresholds $(\mathrm{F}=5.96$, $\mathrm{P}=0.0001$ ). Post hoc analysis by the Tukey test showed that the mean Vernier offset was significantly higher for the younger age groups (5-10 and 11-20 years) and did not 
differ between the other groups. The $95 \%$ confidence interval of the mean Vernier value for each age group was: group $1=3.64$, group $2=3.71$, group $3=2.8$, group $4=2.9$, and group $5=3.12$.

The distribution of the Vernier trials for each subject in each group is presented in Figure 2 where the coefficient of variation (standard deviation/mean) for each subject ranged from 35.8 to $153.1 \%$.

The number of trials necessary to obtain a mean Vernier value with a precision of $10 \%$ is presented in Figure 3 for all subjects. This number was obtained using the formula $\mathrm{n}=\mathrm{t}^{2} \cdot \mathrm{s}^{2} /\left(\mathrm{d}^{2} \cdot \mathrm{x}^{2}\right)$, where $\mathrm{n}$ is the sample size, $t$ is the value of the $t$ distribution with $n '-1$ degrees of freedom and with $5 \%$ probability, $n$ ' is the sample number of measurements, $s^{2}$
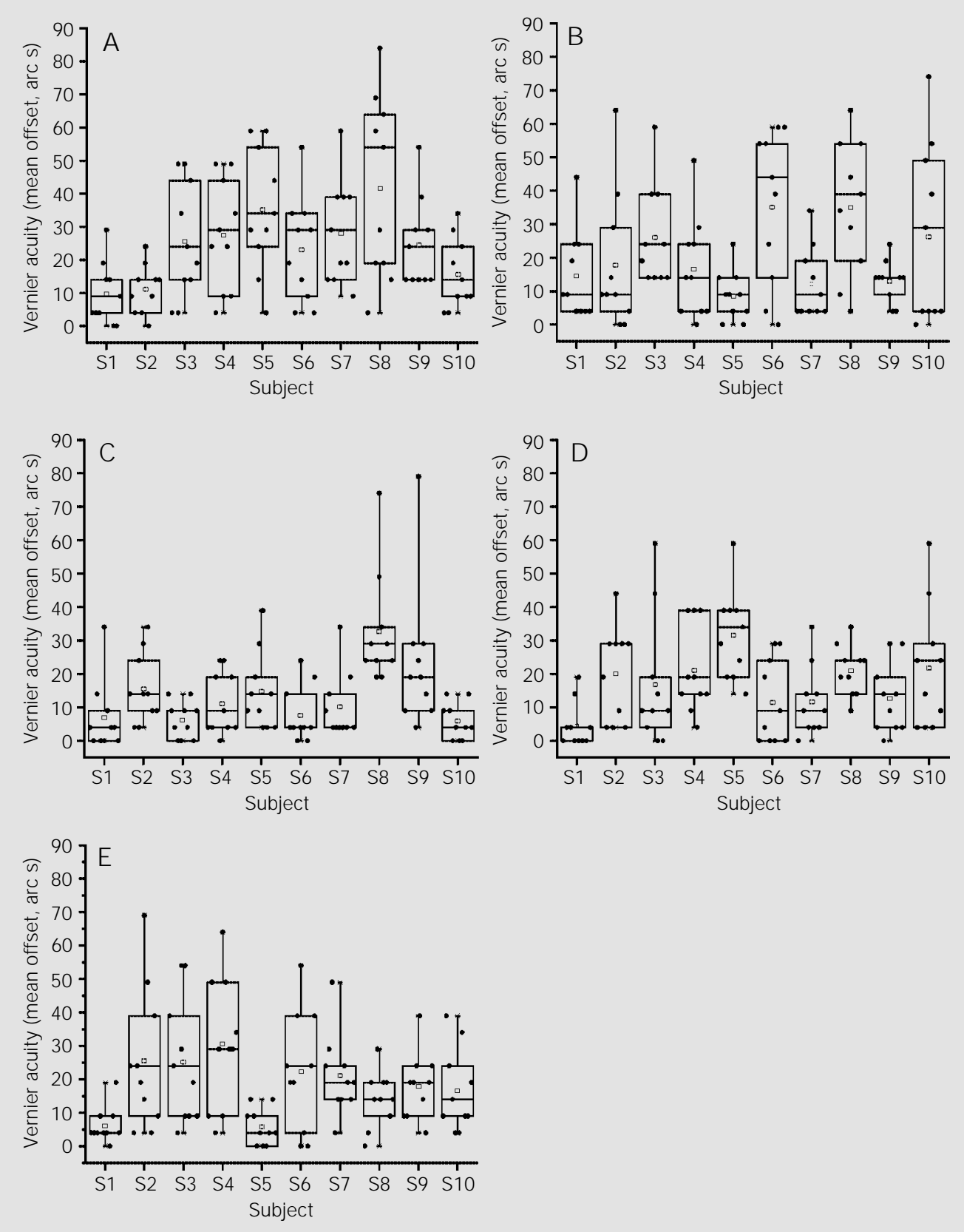
is the variance of the sample measurements, $\mathrm{x}$ is the mean of the sample, and $\mathrm{d}$ is the desired precision $(d=0.1)(20)$.

One-way ANOVA showed that there were no differences in the mean number of trials calculated for the various age groups $(1=$ $230,2=350,3=461,4=421$ and $5=279$; $\mathrm{F}=1.91, \mathrm{P}=0.12$ ).

\section{Discussion}

Since the original description of Vernier acuity in 1892 by Wülfling $(7,11)$, there has been no agreement on the neural mechanisms underlying this type of discrimination. Several types of neural processing have been proposed to account for the extremely low Vernier thresholds obtained under optimal conditions. Most investigators believe that a central process such as interpolation $(2,21,22)$ is involved in the positional resolution. This feature plus the relative insensitivity of Vernier acuity to retinal image degradation (8) explain why Vernier acuity is such a poten-

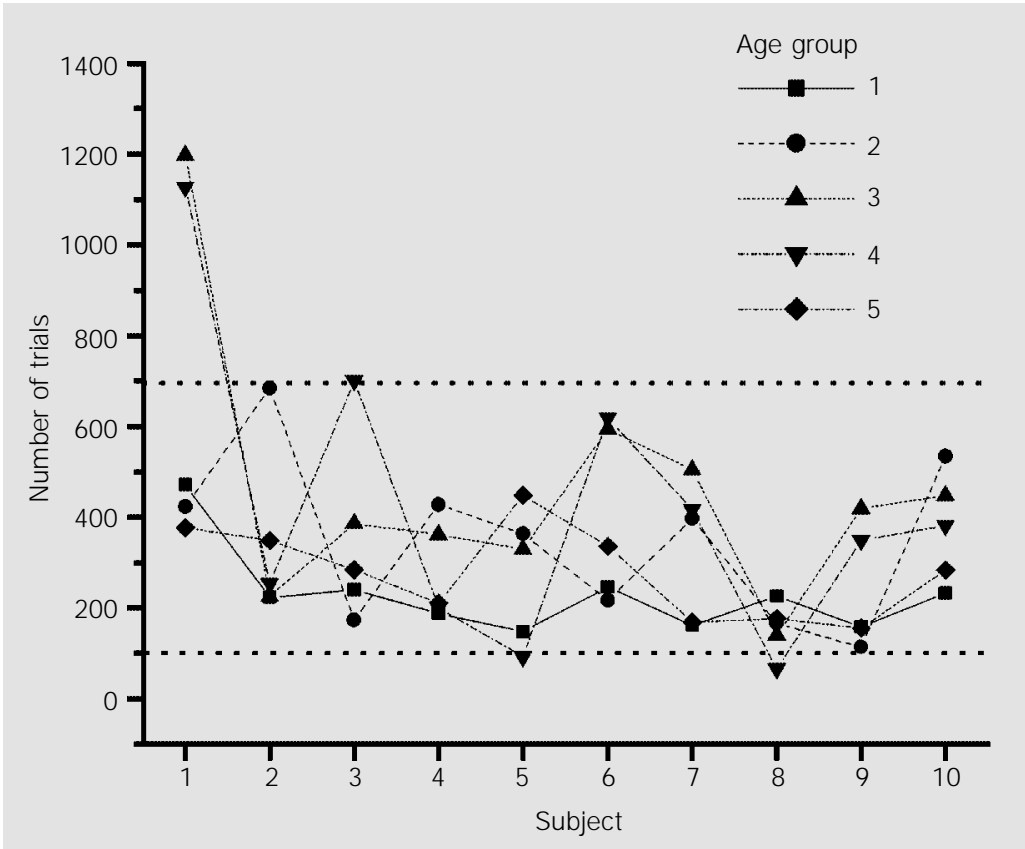

Figure 3. Calculation of number of trials to provide a mean Vemier acuity with a $10 \%$ precision. This number ranged from 66 (subject \#8 of group 4) to 1068 (subject \#1 of group 3). Age groups: $1=5-10,2=11-20,3=21-30,4=31-40$, and $5=41-50$ years. tially useful test for the visual system. Theoretically, high order disorders such as amblyopia would be easily detected with a Vernier paradigm. However, the measurement of Vernier acuity has never been part of the clinical arsenal of visual testing.

The reasons for the resistance of clinicians to use Vernier acuity are not clear. From a pure methodological perspective, the widespread availability of high resolution monitors and computers has eliminated most of the difficulties involved in the generation of Vernier stimuli. The adjustment method, as suggested by some $(2,4)$, is totally appropriate for clinical use. Our subjects understood the nature of the task and were easily tested. The track ball we have used allowed fine variation of the stimulus position and did not offer any difficulty for any subject. Lack of motor coordination was not observed in any patient.

We think that the variability of the positional judgments explains why Vernier acuity is not routinely measured by ophthalmologists. Our results show that for all age groups tested, the number of trials required to measure a mean Vernier threshold value with a confidence interval of $10 \%$ ranged from 100 to 700 . The fact that this number did not differ with age agrees with previous results (4) and indicates that this feature is an intrinsic characteristic of the neural process involved in Vernier acuity. In fact, it is possible that the cognitive ability of our age groups was not the same, with young adults and older subjects being more comfortable than children with a task that requires high levels of attention. Yet, the dispersion of the data was essentially the same for all age groups. An attentional process probably explains why children have higher thresholds than adults, as suggested by some $(23,24)$ and confirmed in the present study.

The variability of the Vernier acuity trials is certainly an obstacle to the clinical use of the procedure. It is important to note that in the vast majority of the psychophysical 
studies on Vernier acuity the number of subjects tested was small and the time needed for training quite long. In their classical paper on the effect of training in Vernier acuity, McKee and Westheimer (1) used more than 2000 responses for each subject. Since then training has become a mandatory procedure for measuring Vernier acuity. Clinicians simply cannot do that during routine examinations.

\section{References}

1. McKee SP \& Westheimer G (1978). Improvement in Vemier acuity with practice. Perception and Psychophysics, 24: 258262.

2. Cox J F, Suh S \& Leguire LE (1996). Vernier acuity in amblyopic and nonamblyopic children. J oumal of Pediatric Ophthalmology and Strabismus, 33: 39-46.

3. Farrell B \& Pelli DG (1999). Psychophysical methods, or how to measure a threshold, and why. In: Carpenter RHS \& Robson J G (Editors), Vision Research: A Practical Guide to Laboratory Methods. Oxford University Press, New York, NY, USA, 129136.

4. Odom J V, Vasquez RJ, Schwartz TL \& Linberg JV (1989). Adult Vemier thresholds do not increase with age; Vernier bias does. Investigative Ophthalmology and Visual Science, 30: 1004-1008.

5. Hirsch J \& Curcio CA (1989). The spatial resolution capacity of human foveal retina. Vision Research, 29: 1095-1101.

6. Curcio CA, Sloan KR, Kalina RE \& Hendrickson AE (1990). Human photoreceptor topography. J oumal of Comparative Neurology, 292: 497-523.

7. Westheimer G (1975). Visual acuity and hyperacuity. Investigative Ophthalmology and Visual Science, 14: 570-572.

8. Williams RA, Enoch JM \& Essock EA
(1984). The resistance of selected hyperacuity configurations to retinal image degradation. Investigative Ophthalmology and Visual Science, 25: 389-399.

9. Wilson HR (1986). Responses of spatial mechanisms can explain hyperacuity. Vision Research, 26: 453-469.

10. Stigmar G (1971). Blurred visual stimuli: II. The effect of blurred visual stimuli on Vernier and stereo acuity. Acta Ophthalmologica, 49: 364-379.

11. Westheimer G \& McKee SP (1977). Spatial configurations for visual hyperacuity. Vision Research, 17: 941-947.

12. Bradley A \& Skottun BC (1987). Effects of contrast and spatial frequency on Vermier acuity. Vision Research, 27: 1817-1824.

13. Westheimer G \& McKee SP (1975). Visual acuity in the presence of retinal-image motion. J oumal of the Optical Society of America, 65: 847-850.

14. Whitaker D \& MacVeigh D (1991). Interaction of spatial frequency and separation in Vemier acuity. Vision Research, 31: 12051212.

15. Westheimer G, Shimamura $K \&$ \& McKee SP (1976). Interference with line-orientation sensitivity. J ournal of the Optical Society of America, 66: 332-338.

16. Fahle $M \&$ Edelman $S$ (1993). Long-term learning in Vernier acuity: effects of stimu- lus orientation. Vision Research, 33: 397412.

17. Essock EA, Williams RA, Enoch JM \& Raphael S (1984). The effects of image degradation by cataract on Vernier acuity. Investigative Ophthalmology and Visual Science, 25: 1043-1050.

18. Levi DM, Polat U \& Hu YS (1997). Improvement in Vernier acuity in adults with amblyopia. Practice makes better. Investigative Ophthalmology and Visual Science, 38: 1493-1510.

19. Levi DM \& Polat U (1996). Neural plasticity in adults with amblyopia. Proceedings of the National Academy of Sciences, USA, 93: 6830-6834.

20. Thompson SK (1992). Sampling. J ohn Wiley \& Sons Inc., New York, NY, USA.

21. Geisler WS (1984). Physical limits of acuity and hyperacuity. J oumal of the Optical Society of America (Part A), 1: 775-782.

22. Braddick O (1984). Visual hyperacuity. Nature, 308: 228-229.

23. Carkeet A, Levi DM \& Manny RE (1997). Development of Vemier acuity in childhood. Optometry and Vision Science, 74: 741-750.

24. Zanker J, Mohn G, Weber U, ZeitlerDriess K \& Fahle M (1992). The development of Vemier acuity in human infants. Vision Research, 32: 1557-1564. 